\title{
A ESCOLA E A VIDA NO CAMPO E NA CIDADE
}

\section{SCHOOL AND LIFE IN THE COUNTRYSIDE AND \\ IN THE CITY}

\author{
Caroline Bellaguarda de Azevedo* \\ Célia Regina Vendramini** \\ Fabiane Marra da Silva Pereira Garcia***
}

Resumo: Procurando superar o histórico antagonismo entre campo e cidade, abordamos neste artigo experiências escolares situadas em acampamentos do Movimento dos Sem Terra, no campo, e experiências vinculadas à Comissão de Educação do Fórum do Maciço do Morro da Cruz, na periferia da cidade de Florianópolis. As escolas pesquisadas são expressão das formas de produção da vida e das formas de organização coletiva dos territórios em que estão situadas, marcadas pela extrema desigualdade social. Com singularidades e elementos em comum, revelam os limites da escola e da vida na atualidade, bem como possibilidades de superação e contraposição ao modo de produção vigente.

Palavras-chave: Desigualdades. Campo e cidade. Movimento dos Sem Terra. Fórum do Maciço do Morro da Cruz. 
Abstract: Looking overcome the historical antagonism between country and city, in this article we discuss school experiences located in encampments in the Landless Workers Movement in the countryside, and experiences linked to Committee of Education in the Forum of the Massif of the Morro da Cruz, on the suburb of the city of Florianópolis. Schools researched are an expression of the forms of life production and forms of collective organization of the territories in which they are located, tagged by extreme social inequality. With singularities and common elements, they disclose the limits of school and life today, as well the possibilities of overcoming and opposition to the current production mode.

Keywords: Inequalities. Countryside and city. Movement of Landless Workers (MST). Forum of the Massif of the Morro Da Cruz (FMMC). 


\section{Introdução}

Nosso propósito neste artigo é analisar a escola a partir do seu contexto, considerando que esta é constituída por relações históricas e espaciais, e reflete, portanto, as contradições da sociedade. A sociedade brasileira, marcada fortemente pela desigualdade social, como expressão de uma realidade cindida pela oposição de classes, conta historicamente com um sistema e estrutura escolar que reflete e reproduz as desigualdades. Nem mesmo o Manifesto dos Pioneiros da Escola Nova, anunciado em 1932, na sua defesa de escola para todos, foi capaz de atingir seu próprio objetivo a equalização de oportunidades e a ascensão social por meio da educação.

Tal propósito, hoje renovado e anunciado como novidade, por meio de políticas e programas compensatórios, insiste na possibilidade de superação das desigualdades sociais por intermédio de políticas educacionais. Políticas estas que, mesmo buscando a equalização, continuam a reservar à classe trabalhadora uma escola e programas educativos diferenciados, os quais flexibilizam e limitam o acesso aos conhecimentos mais avançados concernentes com o desenvolvimento da humanidade.

Neste artigo abordamos a escola com base no contexto em que ela está inserida, observando as relações entre a vida, o trabalho e a educação. Percebemos, por meio de nossa pesquisa, que as desigualdades sociais e econômicas vão se expressar nas diversas dimensões da vida, entre elas a escolar.

Comumente, os estudos sobre a escola situam-se no contexto urbano ou no rural, dificilmente propõem uma análise que articule ambos. Portanto, nos desafiamos a refletir sobre as questões que 
dizem respeito à escola no campo e na cidade, buscando elementos em comum e também suas especificidades, a partir de uma análise que procura articular a singularidade e a universalidade, considerando a teia de relações que liga a escola ao movimento universal de produção da vida na atualidade.

Nosso ponto de partida em termos de análise é a compreensão da categoria território como uma totalidade em que o singular é expressão do universal. Tal categoria possibilita estabelecer a articulação entre campo e cidade para além da dualidade. Território não é sinônimo de região que expressa delimitações geográficas ou político-administrativas, significa o espaço apropriado pelos homens, espelha forças em luta e, por conseguinte, contempla os sujeitos do embate histórico.

O território envolve a natureza e a sociabilidade humana, ou seja, a organização social existente em um determinado espaço e tempo históricos, neste sentido, quem cria o território são os homens e as mulheres pela necessidade do trabalho, pela linguagem e os hábitos que se cultivam conforme a região e os recursos naturais da parte ocupada no globo terrestre.

Para Harvey (2004), a expansão territorial é um elemento-chave para manutenção do sistema capitalista que promoveu a globalização como ferramenta última de reestruturação, rompendo fronteiras, internacionalizando empresas, tendo a tecnologia a seu serviço com os avanços nos meios de transporte e comunicação, ordenando o espaço e o tempo ao seu querer. Segundo Harvey (2004), estas ações do capital produzem espaços geográficos desiguais, miséria, redução dos salários, deterioração das condições de trabalho, destruição do meio ambiente e esgotamento dos recursos naturais. 
Todo este cenário de terror em conjunto com as ideologias dominantes individualistas e fragmentadoras tendem a imobilizar os sujeitos concentrando suas energias exclusivamente na produção de sua sobrevivência. Mesmo em condições tão adversas, Harvey (2004) aponta a possibilidade da criação de espaços de esperança, na busca permanente de elementos comuns unificadores da luta, por meio do debate e da troca de ideias que fermentem o imaginário para criação de uma alternativa social mais humana.

Milton Santos (2009) acredita na possibilidade de outra forma de globalização que tenha o ser humano como pilar central, ao invés do dinheiro, e que propicie a todos as condições de uma vida digna. Aponta que mesmo em meio à escassez e à pobreza podemos encontrar esperança, pois as pessoas sempre buscam novas alternativas de sobrevivência. Santos (2009) acredita que as condições para mudança já estão postas mesmo que em desvantagem no contexto atual, mas haverá o momento propício para sua ebulição.

Objetivamos apreender, neste artigo, em espaços coletivos no campo e na cidade, possibilidades de transformação das condições materiais de vida, bem como experiências escolares que de algum modo estabelecem relação com a comunidade organizada.

Tomamos como referência para a análise pesquisa desenvolvida em contextos marcados pela desigualdade social e escolar no campo e na cidade, mas que contam com lutas e movimentos organizados. São as Escolas itinerantes "Herdeiros da Luta de Porecatu" e "Construtores do Futuro" em acampamentos do Movimento dos Trabalhadores Rurais Sem Terra (MST) no estado do Paraná e a Escola Padre Anchieta, a qual atende crianças e jovens do território conhecido como Maciço do Morro da Cruz, em Florianópolis (SC). Duas realidades distintas mas que apresentam elementos em 
comum, particularmente o atendimento às crianças e jovens da classe trabalhadora, que vivem em áreas periféricas da cidade e do campo no que diz respeito às difíceis condições de vida e de trabalho, bem como de acesso aos bens culturais e aos conhecimentos construídos historicamente pela humanidade. Têm também em comum uma história de resistência, de organização e de luta para alterar sua situação de vida.

Portanto, a pesquisa foi desenvolvida em três diferentes locais: na Escola Padre Anchieta, por meio de questionários aplicados a estudantes dos anos finais do ensino fundamental e do ensino médio, da análise do Projeto Político Pedagógico (2011) da escola, atualmente em estágio de reelaboração, e de visita à comunidade do Morro do Vinte Cinco, onde realizamos entrevista com moradores. Os dois outros locais de pesquisa referem-se às Escolas Itinerantes "Herdeiros da Luta", em Porecatu e "Construtores do Futuro", em que foi feita observação e entrevista com lideranças, moradores e professores dos acampamentos.

\section{O Acampamento e a Escola Itinerante Herdeiros da Luta de Porecatu}

Paraná é um estado de grandes lutas pela terra, já desde a época das Ligas Camponesas nas décadas de 1930-1940 fora uma das arenas mais movimentadas pela disputa da terra. Ainda hoje a concentração de terras está sob o poder e a propriedade de poucas famílias. A monocultura é o tipo de produção predominante no estado ${ }^{1}$.

Diante da enorme concentração de terras no estado, os trabalhadores rurais sem-terra organizados por meio do Movimento 
dos Sem Terra (MST) e lutando pela reforma agrária ocupam terras improdutivas e resistem com produção de alimentos e educação. São homens e mulheres que já não conseguem se reproduzir como trabalhadores rurais, como pequenos produtores ou como arrendatários e juntam-se ao MST buscando imediatamente a sobrevivência, por meio da conquista da terra.

Em $1^{\circ}$ de novembro de 2008, 1,2 mil alqueires de terra ao norte do estado são ocupados inicialmente por 140 famílias. O local fica próximo do rio e além da monocultura, aquele espaço de terra fértil chamada de mancha rocha era também utilizado como depósito do lixo da cidade, incluindo lixo hospitalar. Neste local, cerca de cem famílias estão atualmente acampadas em condições bastante precárias. A organização coletiva de manutenção e segurança do acampamento se dá por núcleos (grupos organizados de famílias), os quais evidenciam o caráter político de busca por outras relações de poder e de organização do espaço.

Os barracos de lona onde vivem os acampados não são próximos entre si, sendo a escola e a venda (pequeno comércio) os espaços de aglutinação das pessoas. Não há luz elétrica, e poucas famílias têm gerador de luz que mantém refrigerador, televisão e iluminação. A água naquela terra brota do chão em qualquer local, no entanto é poluída pela monocultura da cana, o Estado, após pressão, providenciou um esquema de bombeamento de água e filtragem, possibilitando o uso doméstico e o consumo humano e animal.

A produção na terra é restrita por uma série de motivos: tem muitas árvores frutíferas no local e a terra antes muito fértil foi destruída pelo plantio da cana de açúcar, exigindo grande investimento para a sua recuperação, ainda assim há plantações de milho, 
mandioca e feijão. Tem criação de porcos, vacas leiteiras e galinhas e o cavalo é utilizado para o transporte. Plantam sementes crioulas e prezam pela agroecologia.

Diante de tamanha falta de condições materiais de reproduzir a vida somente pela terra, os acampados são obrigados a vender sua força de trabalho. Destinam-se principalmente à construção civil na cidade, à pequena agricultura da região, seja no plantio, seja na colheita. No entanto, nenhum acampado trabalha para a usina de cana de açúcar próxima ao acampamento, como forma de resistência e protesto. O salário, seja ele mensal, seja por empreitada, saca ou diária, fica com a família e esta é livre para contribuir com o acampamento o quanto puder. A contribuição que vai para o coletivo tem a finalidade de financiar as atividades e mobilizações políticas e culturais do acampamento. As famílias recebem três cestas básicas no ano, assim como participam do programa bolsa família.

Hoje, as cem famílias acampadas ocupam uma parte pequena da propriedade do grupo Atala, esta parte corresponde a 1,4 mil alqueires de terra e não ocorreu nenhum despejo desta ocupação popular em Porecatu, ainda que os tensionamentos sejam frequentes. O diálogo é necessário diante da difícil conjuntura do atual governo do estado do Paraná com sua política de proteção da propriedade privada, de criminalização dos movimentos sociais organizados e de fechamento de escolas, principalmente as itinerantes, acompanhando o desmantelamento feito pelo governo PSDB no Rio Grande do Sul, estado pioneiro na criação das escolas itinerantes e também pioneiro no seu fechamento.

A escola itinerante Herdeiros da Luta de Porecatu é uma instituição estadual dentro de um acampamento, atende crianças da 
Educação Infantil e do Ensino Fundamental e segue as orientações educacionais do MST: “[...] pleiteia-se a construção de uma educação transformadora e emancipatória, propondo tanto a modificação da estrutura de funcionamento interno da escola, em termos de gestão e de trabalho pedagógico, quanto a mudança da estrutura político-econômica de nossa sociedade." (VENDRAMINI; MACHADO, 2011, p. 82).

A construção da escola foi feita com o material que sobrou dos barracos, a biblioteca pequena e bem-cuidada é carente em conteúdo, o que evidencia a absoluta falta de atenção do poder público em dar condições para o funcionamento da escola. Os avanços da escola são limitados pois são restringidos pela institucionalidade do estado burguês. A permanência das crianças na escola do acampamento deixa-as menos suscetíveis à violência e aos preconceitos em relação ao MST.

Pela vivência que tivemos na escola e no acampamento, parece-nos que a escola itinerante, ainda que com diversas contradições e dificuldades, apresenta-se como um "espaço de esperança", na medida em que busca construir o novo e pensar as fronteiras territoriais e de sociabilidade pautadas na solidariedade.

\section{O Acampamento 1 de setembro e a Escola Itinerante Construtores do Futuro}

O acampamento, hoje nomeado Pré-Assentamento Egídio Brumetto, é fruto de uma ocupação feita por 230 famílias no dia $1^{\circ}$ de setembro de 2007. A ocupação foi pacífica por parte do MST, inclusive o proprietário e funcionários da fazenda estavam no local 
e saíram sem resistência. Entretanto, após alguns dias, a polícia foi até a área para efetuar o despejo das famílias que resistiram, em dezembro do mesmo ano o braço armado do Estado voltou e efetuou de maneira violenta a ordem de despejo. Foram três dias de negociação e de despejo, os/as Sem Terra e suas famílias foram para Ortigueira, um outro acampamento do MST e após alguns dias retornaram e ocuparam novamente a área, onde permanecem até hoje. Assim que houve a primeira ocupação, os acampados haviam plantado arroz e feijão, com a reocupação da terra colheram e distribuíram na cidade mesmo com as ameaças e preconceitos, conquistando assim apoio de parte da população.

A organização do acampamento se dá por meio de núcleos e brigadas (formas coletivas de organização), funcionando de fato somente a de segurança/disciplina. As condições dos barracos são melhores que as de Porecatu e a distribuição do espaço é menos dispersa, além de terem luz, porém têm maiores dificuldades com a água, a qual não tem pressão suficiente. Existe uma farmácia, que fica em uma das casas que compunha a fazenda, com atendimento do médico da família uma vez por semana. Ficou bastante evidente neste local a religiosidade e a disputa de espaço entre religiões distintas, logo na entrada do Acampamento há uma construção da Igreja Católica, que vem afirmar-se sobre os cultos evangélicos que tem como espaço os barracos dos fiéis.

A produção é individual e coletiva, o que é produzido no coletivo tem como destino a venda e o retorno volta para o caixa do acampamento, para viabilizar as ações coletivas e garantir recurso para a próxima plantação. Na produção individual, o retorno é para a própria família. Produzem em geral arroz, feijão, milho, batata doce, mandioca, a produção predominante é de leite, com 
ordenha manual. O leite é destinado para uma associação, que o revende para uma rede de supermercados da região.

Mesmo diante de melhores condições para a produção na terra, em comparação com o Acampamento em Porecatu, se faz necessária a venda da força de trabalho, na época de colheita do café, em que os trabalhadores recebem por empreitada ou por saco de $40 \mathrm{~kg}$, e também no cuidado de roças com a aplicação de venenos.

A escola itinerante chama-se Construtores do Futuro e atende crianças da Educação Infantil e Ensino Fundamental. Esta funcionava nas casas que já existiam na fazenda ao ser ocupada, no entanto, as famílias acharam melhor construir a escola conforme a luta, em círculo, caracterizando a coletividade. Os problemas e necessidades são os mesmos de qualquer escola que busque elementos contrários à ordem capitalista em seu projeto político pedagógico, como a falta de estrutura e professores comprometidos com a luta.

A escola dialoga diretamente com o acampamento passando por todos as decisões quanto aos rumos da mesma e os problemas que podem existir em relação aos educandos. Buscam a formação de jovens do próprio movimento para ensinar as crianças, o que é um avanço quando combinado com formação política e pedagógica do próprio movimento.

\section{A Escola Padre Anchieta e a Comissão de Educação do Fórum do Maciço do Morro da Cruz}

De acordo com Dantas (2012), as ocupações mais antigas do maciço do morro da cruz ocorreram na comunidade do Mont Ser- 
rat "[...] ainda no século XIX por escravizados fugidos, recém-libertos e militares pobres." (p. 50). Também se estabeleceram no maciço pequenos agricultores vindos do meio-oeste catarinense e planalto serrano e se constituem na força de trabalho para construção civil florianopolitana, muitos na época da construção da ponte Hercílio Luz.

A mobilização em torno do processo democrático do conselho comunitário de Mont Serrat, sob a liderança do Padre Vilson Groh, que reside na comunidade desde a década de 1980, e a extensão desta mudança para outras unidades do maciço alguns anos mais tarde (final dos anos 1990) gerou o Fórum do Maciço do Morro da Cruz. Este se apresenta como uma forma de articulação entre as comunidades que o integram a fim de buscar soluções à suas demandas comuns: falta de abastecimento de água, energia elétrica, tratamento de esgoto, moradia, transporte público precário e insuficiente.

O FMMC era composto pelas seguintes comissões: segurança, comunicação, meio ambiente, trabalho e renda, sendo a Comissão de Educação (CE) a última a se integrar e a que permanece até os dias de hoje. A primeira reunião com a participação do representativo das escolas que atendiam comunidades do FMMC se deu no dia 30 de outubro de 2000 (COMISSÃO DE EDUCAÇÃO apud DANTAS, 2012, p. 34), em chamada emergencial para discutir a violência e seus efeitos nas escolas que acarretava em impedimento ao acesso dos estudantes de determinadas comunidades a frequentarem as aulas, devido a disputas por ponto de venda de drogas por traficantes.

A Comissão de Educação objetivou auxiliar as escolas na reformulação de suas propostas político-pedagógicas, a fim de que 
estas estivessem mais voltadas à realidade do público da comunidade atendida, considerando as desigualdades que sofrem e deixando de apontá-los como culpados pelo fracasso escolar, seja por repetência, seja por evasão, visando um ensino mais democrático na direção da emancipação.

Apesar dos esforços, muitos foram os percalços que impediram avanços mais significativos na trajetória da CE, entre eles Dantas (2012) cita: a dependência financeira que se restringia aos projetos das universidades públicas; a falta de correspondência entre as demandas postas pelas escolas para formação continuada e as atividades que efetivamente eram oferecidas, acarretando desinteresse dos participantes; sobrecarga de um pequeno número de professores que estavam concretamente envolvidos no FMMC, em suma, muito do que era debatido e articulado se limitava ao plano teórico, não avançando para a prática educativa.

A escola Padre Anchieta, lócus de nossa pesquisa, é vinculada à Comissão de Educação do FMMC desde a sua origem. Ela fica localizada na rua Rui Barbosa, número 525, no bairro Agronômica, região central de Florianópolis, atende a um público de 1024 alunos, destes 28\% moram nos morros Horácio, Santa Vitória, Nova Palestina, Vinte Cinco e Nova Trento. O quadro docente é composto por cinquenta professores, 35 efetivos e 15 em regime de contrato temporário.

Conforme o Projeto Político Pedagógico (2011, em elaboração), a escola foi fundada em 1929 em uma casa alugada sendo inicialmente denominada Escola São Luiz, passou a grupo escolar em 1934, mas sua autorização como Escola Básica Padre Anchieta com ampliação do ensino fundamental até oitava série só ocorreu em 1971, e posterior ampliação ao nível médio em 1985. A última 
reforma no prédio da instituição que também realizou a construção do ginásio foi em 2002.

O edifício escolar conta com amplo espaço físico, porém nem todos adequadamente equipados e em condições de uso: auditório, ginásio, sala multimídia, laboratório de informática e de ciências, biblioteca, sala de artes, sala de professores, secretaria, dispensa, refeitório, salas de administração escolar, direção e de especialistas em assuntos educacionais, 21 salas de aula, seis banheiros para alunos e dois para professores, sala do grêmio estudantil e cabine de rádio atualmente sem uso.

Conforme depoimento da diretora, a escola tem capacidade para atender um público de dois mil alunos, mas conta atualmente com pouco mais de mil matrículas. Essa grande redução do número de estudantes é fato comum nas escolas que atendem as comunidades do maciço, questão esta que merece pesquisas.

A seguir apresentamos uma síntese da análise dos 154 questionários aplicados junto aos estudantes do ensino médio (113) e das séries finais do ensino fundamental (41) da escola Padre Anchieta referentes aos aspectos históricos das comunidades atendidas, suas formas de organização coletiva, produção da vida, condições de infraestrutura e relações estabelecidas com a instituição escolar.

A maior parte dos estudantes é natural do município de Florianópolis, mas um elevado número veio de outros estados, o que representa mudança na constituição desta população local, pois, conforme Dantas (2012), a população destas comunidades em sua maioria era constituída de pessoas vindas do próprio estado, da serra e meio-oeste catarinense, já que Santa Catarina possui o mais elevado índice de êxodo rural do Sul do país. Os estudantes desconhecem as origens de suas comunidades, mas apontam a 
busca por trabalho e moradia como possíveis causas para ocupação dos morros.

Dos membros da família que trabalham, as mães representam maior número economicamente ativo e com registro em carteira, seguidas dos pais e outros integrantes familiares incluindo os estudantes. Das áreas de trabalho em que as famílias estão inseridas se destacam o serviço doméstico, comércio, serviço público e construção civil.

Os alunos, em sua maioria, não trabalham. Dos que declararam trabalhar, as respostas com maior número de estudantes são de estagiários (21) ou empregados no comércio (10). Quanto ao período de trabalho, a maior parte dos estudantes trabalhadores respondeu que trabalhava oito horas, assim como os adultos da família, o que representa uma dificuldade para os estudos. Como muitos alunos trabalham o dia todo e estudam a noite, o ensino acaba se tornando mais precário, com redução de horas-aula e atividades limitadas ao tempo em sala, pois os estudantes não encontram na vida de trabalhador outro momento para se dedicar à sua formação educacional. Além disso, chegam à escola já cansados após uma longa jornada de trabalho, ou deixam de frequentar a escola assiduamente.

No que se refere à renda familiar, 54 alunos responderam ser de até dois salários mínimos, 38 até três salários, 31 até quatro salários, 18 um salário, 2 menos de um salário, sete não responderam e 3 estudantes declararam não saber o valor da renda da família. Como complemento à renda familiar, apenas 22 estudantes afirmaram receber o recurso de Bolsa-Família ou Bolsa-Escola.

$\mathrm{Na}$ questão que trata das condições de trabalho dos pais, quase todos os estudantes relataram ser boa, resposta questionável já que 
podemos constatar que muitos destes adultos trabalham informalmente sem qualquer amparo legal.

No que diz respeito às condições de infraestrutura existentes na comunidade, como coleta de lixo, água encanada, posto de saúde, transporte próximo de casa, escola, creches e parques, conforme questionário respondido pelos alunos, os aspectos ausentes nas localidades onde moram são apresentados abaixo:

- Parques: retrato da política administrativa da cidade que na busca pelo capital turístico não se preocupa em ofertar lazer público à população;

- Tratamento de esgoto: um grande problema de Florianópolis, de acordo com dados da Companhia Catarinense de Águas e Saneamento, o atendimento se limita a apenas $51,1 \%$ da população da cidade $^{2}$;

- Postos de saúde: de acordo com a Prefeitura Municipal de Florianópolis, na região central há cinco unidades de saúde, para atender 85 mil habitantes, destes apenas um está localizado na área do maciço, o posto de saúde do Mont Serrat ${ }^{3}$.

Dos principais problemas das comunidades em que residem, a maior parte dos estudantes indica o tráfico de drogas, resposta que pode auxiliar na questão acerca do destino dos muitos adolescentes e jovens evadidos da escola.

Das instâncias de organização coletiva, foram citadas pela maioria dos estudantes o Fórum do Maciço do Morro da Cruz e os centros comunitários, mas na questão que indagamos sobre a participação familiar nestes espaços, dos 154 alunos 131 responderam não participar de nenhuma associação. Percebe-se que há um conhecimento superficial da importância deliberativa destas 
coletividades, o pouco que conhecem se remete às relações estabelecidas com a Comissão de Educação.

\section{Campo e cidade: espaços de esperança?}

O que a realidade da vida do campo e da cidade acima apresentadas informam? O que há em comum entre elas e o que as distingue? Em termos de produção da vida, observamos a luta dos trabalhadores pela sobrevivência, alguns limitando-se às alternativas individuais e outros buscando soluções coletivas, mas todos dentro do processo capitalista de produção, que impõe ao trabalhador a exploração, a submissão e, atualmente, a informalização das relações de trabalho.

O que há em comum nas formas de produção da vida é o trabalho social e universal e a produção de excedentes para o capital, além do crescente consumo de produtos industrializados fabricados em diferentes regiões do globo. Umbelino de Oliveira (1994), nessa perspectiva, compreende a organização do trabalho na atualidade como um "processo avançado de cooperação", diferente da época de consolidação do capitalismo, em que a separação do campo e da cidade envolvia "trabalhadores individuais, camponeses, artesãos, aqueles que com o trabalho da família quase tudo produzia”. Conforme o autor, a produção de qualquer produto na atualidade não pode mais prescindir do trabalho coletivo, daí a integração entre agricultura e indústria e a eliminação da separação entre campo e cidade (OLIVEIRA, 1994, p. 54).

Em relação às escolas, seja nos acampamentos, seja na periferia da cidade, elas contam com reduzido financiamento do poder 
público, o qual, pela sua natureza no contexto da sociedade capitalista, não tem compromisso com as instituições públicas, como educação, saúde, transporte, lazer e outros. No caso das escolas itinerantes nos acampamentos, observamos uma precariedade muito maior, pela sua "provisoriedade" (ainda que muitos acampados permaneçam anos em barracos de lona lutando pelo assentamento definitivo) e por se caracterizarem como espaços de resistência e luta de um movimento que se coloca em oposição ao agronegócio, ao capital e ao Estado capitalista. Portanto, os sem-terra são penalizados duplamente, por serem trabalhadores e por lutarem por seus direitos.

Além disso, as escolas rurais no Brasil historicamente têm estado em desvantagem, apresentando menores níveis de escolarização e maiores índices de reprovação, abandono e defasagem idade-série. Conforme dados do DIEESE (apud SAPELLI, 2013, p. 1), o analfabetismo rural é três vezes maior que o urbano, 9,5\% das escolas do campo não tem luz elétrica, as bibliotecas são reduzidas, presentes em apenas 25\% das escolas, além da desigual formação profissional entre os educadores do meio rural e do urbano.

$\mathrm{Na}$ periferia da cidade, observamos o fechamento de escolas públicas e a diminuição do número de alunos (algo que merece ser investigado). No campo, há muito tempo escolas vêm sendo fechadas, em função do êxodo rural. Com a luta dos movimentos sociais, particularmente do MST por meio da constituição dos acampamentos e assentamentos, muita pressão tem sido feita pela reabertura e construção de novas escolas.

Pelo exposto, a desigualdade social e escolar é a realidade presente e histórica nos espaços pesquisados, a qual não tem sido re- 
vertida por meio de programas e políticas compensatórias. Segundo nossa avaliação, a luta, organização e pressão dos movimentos e organizações dos trabalhadores é que tem tido algum alcance para a conquista de escolas, o acesso das crianças e jovens à escolarização em diferentes níveis e a disputa por seus programas e currículos.

Não encontramos na escola da cidade uma forte organização política, mas pelo seu histórico de lutas e conquistas junto à Comissão de Educação do FMMC, observamos avanços. Entendemos que se faltou ao espaço coletivo como um todo esperança, isso não impediu que os poucos que conservaram este sentimento objetivassem reconstruir na coletividade as possibilidades de mudanças no seu contexto social.

Nas escolas do Movimento dos Trabalhadores Rurais Sem Terra em geral, observamos uma forte organização pela construção de escolas, pela contratação de professores, por recursos materiais e, particularmente, por uma pedagogia que se contraponha à escola capitalista e seus propósitos educacionais. Estes espaços de resistência em busca da produção de um outro tipo de vida e de educação, orientada por valores como a solidariedade, a coletividade e a autogestão, mostram que existem "espaços de esperança”.

As experiências escolares pesquisadas, por meios diferentes, estabelecem relação com a comunidade no seu entorno, a qual, em condições precárias de vida e de trabalho, ainda resiste e tem expectativas em relação à escolarização de suas crianças e jovens.

Questionamos neste artigo as relações dominantes que tem por base a divisão social do trabalho, a qual cria uma dualidade entre o trabalhador do campo e o trabalhador da cidade, entre a escola rural e a escola da cidade, colocando o campo e a cidade em oposição. 
Fica evidente a necessidade da busca de formas de superação da sociedade moderna, dos antagonismos e oposições, como entre campo e cidade, das cisões na própria ciência e da divisão do trabalho e do conhecimento que marca os conteúdos escolares e a organização da escola.

A transformação das forças produtivas e dos meios de produção implica também a transformação das condições subjetivas do ser humano, de sua sociabilidade. Como Alexandra Kollontai (1982) apresenta em sua reflexão sobre a revolução bolchevique e a moral revolucionária, ao relatar os dramas de um casal de jovens revolucionários que vivendo o socialismo depararam-se com as contradições e conflitos pessoais da sociabilidade dos valores burgueses em conflito com a moral revolucionária. Ou Meszárós (2008), em A educação para além do capital, que apresenta que a transformação material deve vir junto com a transformação da consciência, pois não basta às classes trabalhadoras ter o poder político e econômico sem alterar as bases educacionais da sociedade, desde o íntimo das suas relações pessoais, familiares, de comunicação e escolares.

\section{Referências}

DANTAS, Jéferson Silveira. Espaços coletivos de esperança: a experiência política e pedagógica da Comissão de Educação do Fórum do Maciço do Morro da Cruz em Florianópolis/SC. 2012. Tese (Doutorado em Educação) - Universidade Federal de Santa Catarina, Florianópolis, 2012.

ESCOLA PADRE ANCHIETA. Projeto Político Pedagógico. Florianópolis, 2001. 
FREITAS, L.C. A luta por uma pedagogia do meio: revisando o conceito. In: PISTRAK, M. M. A escola-comuna. Trad. de Alexandra Marenich e Luiz Carlos de Freitas. São Paulo: Expressão Popular, 2009.

HARVEY, David. Espaços de esperança. São Paulo: Loyola, 2004.

IBGE. Censo Agropecuário de 2006. Disponível em: <http://www. ibge.gov.br/home/estatistica/economia/agropecuaria/censoagro/2006/ default.shtm>. Acesso em: 22 fev. 2013.

KOLLONTAI, Alexandra. Irmãs. In: A nova mulher e a moral sexual. São Paulo: Global, 1982.

MESZÁROS, Istvan. A educação para além do capital. 2. ed. São Paulo: Boitempo, 2008.

MOVIMENTO DOS TRABALHADORES RURAIS SEM TERRA. MST Escola. Caderno de educação, n. 13, edição especial. Setor de educação do MST. Veranópolis: ITERRA, 2005.

OLIVEIRA, A. U. O campo brasileiro no final dos anos 80. In: STÉDILE, J. P. (Org.). A questão agrária hoje. 2. ed. Porto Alegre: Editora da Universidade UFRGS, 1994.

SANTOS, Milton. Por uma outra globalização: do pensamento único à consciência universal. 18. ed. Rio de Janeiro: Record, 2009.

SAPELLI, Marlene L. S. Escola do campo - espaço de disputa e de contradição: análise da proposta pedagógica das Escolas Itinerantes do Paraná e do colégio Imperatriz Dona Leopoldina. 2013. Tese (Doutorado em Educação) - Universidade Federal de Santa Catarina, Florianópolis, 2013.

VENDRAMINI, Célia R.; MACHADO, Ilma F. A relação trabalho e educação nas experiências escolares do MST. In: VENDRAMINI, C. R, MACHADO, I. F. (Orgs.). Escola e movimento social: a experiência em curso no campo brasileiro. São Paulo: Expressão Popular, 2011. p. 79108. 


\section{Notas}

* Estudante do curso de Ciências Sociais da Universidade Federal de Santa Catarina. Membro do Núcleo de Estudos sobre as Transformações no Mundo do Trabalho (TMT). E-mail: <carobellag@gmail.com>.

** Doutora em Educação. Professora do Centro de Ciências da Educação da Universidade Federal de Santa Catarina. Membro do Núcleo de Estudos sobre as Transformações no Mundo do Trabalho (TMT). Bolsista Produtividade do CNPq. E-mail: <celiavendram@gmail.com>.

${ }^{* * *}$ Estudante do curso de Pedagogia da Universidade Federal de Santa Catarina. Membro do Núcleo de Estudos sobre as Transformações no Mundo do Trabalho (TMT).E-mail: <jireh_fs@yahoo.com.br>.

${ }^{1}$ Segundo o censo do Instituto Brasileiro de Geografia e Estatística (IBGE) de 2006, o número de estabelecimentos no estado passou, de 1970 a 2006, de 554.488 para 373.238 , e a área ocupada por estes passou de 14.625 .530 para 17.568.089 hectares, ou seja, houve um aumento na área, mas uma diminuição no número de propriedades. O Paraná foi o estado brasileiro em que mais se diminuiu o número de pessoas ocupadas no campo. Em 1970 eram 1.981.471, passando em 2006 para 1.097.438 de pessoas (dessas, 868.774 com laços de parentesco com o produtor e 228.664, sem laços de parentesco). Quanto à ocupação das áreas, em 2006, 8.090.963 de hectares estavam ocupadas pelas lavouras; 5.735 .095 hectares por pastagens e 3.172 .889 hectares por matas e florestas.

${ }^{2}$ Disponível em: <www.casan.com.br>. Acesso em: 25 jun. 2012.

${ }^{3}$ Disponível em: <www.pmf.sc.gov.br>. Acesso em: 25 jun. 2012. 